\title{
A 'VERDADE' DA CIÊNCIA A PARTIR DE UMA LEITURA PSICANALÍTICA
}

\author{
Elizabeth dos Reis Sanada ${ }^{1}$ \\ Instituto de Psicologia - USP
}

\begin{abstract}
O presente trabalho tem como objetivo situar de que maneira a ciência se torna a principal representante do discurso social, assumindo a função de nomeação do sujeito no mundo moderno, sendo responsável pela produção de objetos que visam ao suturação da falta. Discute o ponto de conexão entre o discurso da psicanálise e o da ciência no que concerne à divisão do sujeito entre saber e verdade.
\end{abstract}

Descritores: Ciência. Psicanálise. Verdade. Prazer.

\begin{abstract}
Com base em textos de Lacan como "A Ciência e a Verdade" (19651966/1998) e O Avesso da Psicanálise (1969-1970/1992) o presente trabalho tem como objetivo situar de que maneira a ciência se torna a principal representante do discurso social, assumindo a função de mmeação do sujeito no mundo moderno, sendo responsável pela produção de objetos que visam ao suturamento da falta, favorecendo o surgimento de novas categorias sintomáticas, como as síndromes do pânico, as toxicomanias, as depressões, entre outras.
\end{abstract}

Neste sentido, o que Lacan (1965-1966/1998, p. 889) nos diz em “A Ciência e a Verdade" é que a ciência se caracterizaria por uma disjunção dos campos da verdade e do saber, algo que deixa claro ao enfatizar que "a pro-

1 Doutoranda do Programa de Pós-Graduação em Psicologia Escolar e Desenvolvimento Humano, Instituto de Psicologia - USP. Bolsista do CNPq. Endereço eletrônico: bethreissanada@aol.com 
digiosa fecundidade de nossa ciência deve ser interrogada em sua relação com o seguinte aspecto, no qual a ciência se sustentaria: que, da verdade como causa, ela não quer-saber-de-nada".

Torna-se importante ressaltar que essa disjunção é o que marca a própria constituição do sujeito, dividido, uma vez que se estabelece uma relação de razão entre $S_{1}$ e $S_{2}$, ponto este, a princípio, que equivaleria aos discursos da ciência e da psicanálise em sua essência. No entanto, uma diferença fundamental se coloca, e diz respeito à exclusão do sujeito por parte da ciência, sujeito este que a psicanálise busca reintroduzir em seu discurso, contemplando a dimensão da verdade como não-toda a partir da fala, e a dimensão do saber naquilo que se articula à cadeia significante.

Sendo assim, é justamente essa disjunção entre verdade e saber que Lemérer (1999) situa como sendo o que permite à ciência se ocupar do que é sexual. Entretanto, diferentemente da psicanálise, o sexual aqui se encontra reduzido a seu puro real biológico, excluindo-se qualquer implicação de um sujeito.

Vários autores se detiveram no estudo do discurso científico e de sua relação com a subjetividade. Entre eles, encontra-se Jerusalinsky (s.d., p. 3), que, referindo-se mais especificamente à ciência positivista, considera que cada ciência visa a produzir um conhecimento capaz de responder ao que há de insuportável frente ao não-saber sobre o objeto. "Cada ciência faz seu recorte do objeto e traça uma borda - seja em teoria ou tecnologia - ao redor dele".

Trata-se, segundo o autor, de uma tentativa de "constituir uma borda significante destinada a conter o buraco de ignorância", a responder à emergência de um real que se torna insuportável para esses sujeitos.

O fundamental a se recortar do texto de Jerusalinsky (s.d.) diz respeito ao modo como essa borda para o real se compõe, isto é, a partir de significantes que estão situados no discurso de um, ou que estão situados numa fantasmática coletiva, ou seja, no que se chama discurso. 
Jerusalinsky nos diz que "discurso alude a uma fantasmática coletiva, e isto torna permissível que, nesta práxis discursiva, os significantes não signifiquem a mesma coisa para todo mundo" (p. 3).

Se os significantes se distinguem na esfera do particular, o que se coloca como uma crítica ao discurso da ciência é, propriamente, o fato deste discurso buscar um suturamento do sujeito, a partir de uma universalização dos conceitos e dos instrumentos que produz.

Neste sentido, apontamos para dois níveis em que se dá essa busca de escamoteamento da falta: primeiramente, no que se relaciona ao modo como o corpo é concebido pela ciência e, posteriormente, na equivalência que se traça entre sujeito e objeto, a partir da produção de instrumentos que subtraem do sujeito seu saber.

No primeiro caso, Unterberger (1999, p. 64) descreve o discurso da ciência como sendo uma forma do discurso do mestre, que se caracteriza por produzir um saber no real. Desta forma, o corpo, nesta acepção, é tomado como organismo, distinguindo-se do corpo afetado pela linguagem e, portanto, do corpo no sentido libidinal. Conclui esse autor: "ao obliterar a dimensão do gozo, o corpo é tratado como um cadáver que é objeto de investigação". Como conseqüência mais imediata, vemos que o sujeito não se implica em seu sintoma.

Vê-se articular uma tentativa de pôr em jogo uma outra forma de gozo, tentativa esta que discutiremos retomando as palavras de Alvarez (1995, p. 80), ao dizer que "o que a ciência impõe a todos é a universalização dos laços sociais a cada vez que, com uma infinidade de objetos de consumo propõe suturar a divisão do sujeito".

Para Unterberger (1999, p. 64), o que se promove a partir desse discurso é a coletivização de uma mesma maneira de gozar,

ali onde a lei não opera para pôr limites, propõem-se normas que funcionam como suplências da lei do sujeito articulado ao desejo. Uma intenção de recomendar com uma norma "para todos", o que não é senão uma particularidade de estrutura e peculiar da posição subjetiva. 


\section{Elizabeth dos Reis Sanada}

Novamente nos deparamos com uma busca de fechamento, ao mesmo tempo em que algo da história se exclui. Como o próprio Lacan (19651966/1998, p. 884) propunha, eis mais uma característica da ciência, o fato de não ter memória. "Ela esquece as peripécias em que nasce uma vez constituída..."

De que concepção de sujeito estaríamos a falar neste contexto?

Introduzimos, neste ponto, uma diferença entre o que anteriormente constituía a idéia de um sujeito passivo, do sujeito estímulo-resposta e o que se apresenta atualmente como um reflexo do mundo moderno, ou seja, o sujeito como um sistema de processamento de informação - fruto do cognitivismo -, diríamos: um sujeito mais próximo da idéia de máquina.

A esse respeito, Rivière (citado por Sillitti, 1994, p. 54) afirma que "a psicologia cognitiva é uma das manifestações mais claras do zeitgeist científico, a organização tecnológica e certos interesses produtivos dominantes". Sillitti (1994, p. 54) acrescenta que, deste lugar, o que se apresenta é um sujeito processador, o sujeito programado: "Um sujeito que possa responder ao drama de sua existência com um 'faltam dados'. Frente ao que chamam os 'problemas de organização do sujeito', opõem os 'problemas de organização do conhecimento"'. Trata-se, nesta vertente, de um sujeito sem falta, na medida em que os dados que lhe faltam no processador podem ser computados a qualquer momento. Não há nessa dinâmica nada que marque ao sujeito a impossibilidade de acesso a um gozo capaz de responder ao que se coloca como falta-a-ser.

No entanto, haveria uma incongruência interna que, sob a promessa de um gozo Outro, põe o sujeito frente a uma falta - não aquela, estruturante, mas a fabricada a partir de objetos que engendram necessidades no lugar do desejo, produtos da ciência, as quais colocam o sujeito em busca do objeto ideal capaz de suturar-lhe a falta.

Tudo que se produzir como hiância, por essa via, será percebido pelo sujeito como impotência, e não como impossibilidade de acesso/conjugação do sujeito ao seu fantasma. 
Neste ponto, fazemos nossas as pala vras de Sinatra (1994, p. 26), considerando que é "desde o discurso do mestre que se oculta o que seria o ideal da identidade do significante, a verdade de um sujeito dividido, em relação à sua causa".

Faz-se necessário, portanto, verificar de que maneira a ciência ocupa os discursos trabalhados por Lacan (1969-1970/1992), no Seminário $O A$ vesso da Psicanálise.

Neste seminário, Lacan busca distinguir o que está em questão no discurso como uma estrutura, colocada por ele como excedente à palavra.

Atribui à linguagem a possibilidade da existência de relações estáveis que ultrapassam o campo das enunciações efetivas. Para isto, articula como estrutura mínima da linguagem a proposição de quatro termos - a saber, $\mathrm{S}_{1}$, $\mathrm{S}_{2}, \$$ e $a$ - que giram numa determinada ordem denominada por Lacan de quadrípodes e que originará quatro estruturas, quatro discursos distintos, conforme o posicionamento desses termos.

A partir dessa proposição, discute as funções próprias do discurso, começando pelo do mestre, cuja estrutura dá origem ao discurso da histérica, da universidade e do analista.

Neste sentido, o que Lacan (1969-1970/1992, p. 13) circunscreve como sendo o essencial da estrutura é que

é no instante mesmo em que o $\mathrm{S}_{1}$ intervém no campo já constituído dos outros significantes $\left(\mathrm{S}_{2}\right)$, na medida em que eles já se articulam entre si como tais, que, ao intervir junto a um outro do sistema, surge isto, $\$$, que é o que chamamos de sujeito como dividido.

E acrescenta: "Enfim, nós sempre acentuamos que desse trajeto surge alguma coisa definida como uma perda. É isto que designa a letra que se lê como sendo o objeto $a$ ” (p. 13).

É justamente nessa operação que Lacan (1969-1970/1992) situa o nascimento da ciência, a partir do momento em que se extraiu da relação entre $S_{1}$ e $S_{2}$ a função do sujeito, operação que ele atribui a Descartes, a partir da criação do cogito cartesiano "penso, logo sou". 


\section{Elizabeth dos Reis Sanada}

Em outras palavras, ao localizarmos a ciência no discurso do mestre, dizemos que ela passa a ocupar o lugar de $\mathrm{S}_{1}$, a dominante que faz trabalhar o saber, tendo como efeito um sujeito dividido em relação à verdade como causa. O saber, neste caso, se encontra representado pelo escravo, aquele que sabe sobre o desejo do senhor e que põe a máquina a funcionar.

No que se refere especificamente ao saber, Lacan (1969-1970/1992, p. 28) o descreve como "algo que liga, em uma relação de razão, um significante $S_{1}$ a um outro significante $S_{2}$ ", fazendo surgir $\$$. No entanto, ele enfatiza que "é justamente na medida em que tal relação não se sabe, que reside a base do que se sabe". Este ponto, já abordado anteriormente por Lacan (1965-1966/1998) em "A Ciência e a Verdade", é o que lhe permite elucidar o que se dá em termos do discurso da ciência, no que este vem substituir o lugar do antigo senhor. O que faz o discurso científico? Exime-se da verdade, na medida em que adota o saber como absoluto, tomando-o na via do conhecimento e, portanto, impedindo que se coloque algo do real em jogo.

O que se evidencia nesse processo, segundo Sinatra (1994, p. 25), é a estrutura mesma de nossa civilização: "a existência, agora sustentada pelo pensamento cartesiano, deve dar resposta, na modernidade, à falta primordial de acordo entre os sexos".

Para isto, uma mudança se revela no interior mesmo do discurso do mestre e se verifica na sociedade moderna pelo triunfo do capitalismo, o que é demonstrado por meio da produção de bens de consumo, que rapidamente cobrem os mercados internacionais, mais além de nacionalidades, línguas e ideologias, contribuindo, ainda mais, para colocar o sujeito na categoria de objeto.

Segundo Lacan (1969-1970/1992, p. 169), "alguma coisa mudou no discurso do mestre a partir de certo momento da história (...). A partir de certo dia, o mais-de-gozar se conta, se contabiliza, se totaliza. Aí começa o que se chama de acumulação de capital".

Neste sentido, Sinatra (1994) descreve o mais-de-gozar como a resultante do recobrimento de dois mercados: o mercado da produção e o mercado do saber. Haveria a produção de um gozo do saber que se cotizaria no 
mercado - produção entrópica de gozo -, já que o gozo adequado à complementação dos sexos não existe. Como consequiência da falta-em-gozar elabora-se um plus, excesso a respeito do que não há, mas defeito a respeito do gozo pretendido por cada um.

$\mathrm{O}$ discurso do mestre, segundo o mesmo autor, ocultaria a verdade do processo, "seu efeito de divisão subjetiva - e a produção desse mais-degozar que se desprende desse trabalho do saber -, saber que no escravo se punha a funcionar a partir da ordem do amo" (Sinatra, 1994, p. 26).

Essa mudança no discurso do mestre acarreta conseqüências que se fazem perceber no nível do saber e desencadeia a formulação de dois outros discursos: o da universidade e o do capitalista. No caso do discurso universitário, dá-se a substituição de algo que se colocava no discurso do mestre como um não-saber-de-tudo, por algo que agora se constitui como um tudosaber.

A esse respeito, Lacan (1969-1970/1992) descreve que, no discurso da universidade, o tudo-saber passa para o lugar do senhor e, no lugar da verdade, o que se tem é um significante de senhor.

A verdade deve ser produzida pelos que substituem o antigo escravo, isto é, pelos que são eles próprios produtos, como se diz, consumíveis tanto quanto os outros. Sociedade de consumo, dizem por aí. Material humano... (p. 30)

Desta forma, o discurso da universidade é o que mais se assemelha ao sistema econômico e científico, vigente na contemporaneidade. Lacan (1969-1970/1992) nos diz ainda que, neste discurso, o proletariado é despossuído de seu saber, é frustrado pela exploração capitalista que o torna inútil. O que lhe é devolvido, em uma espécie de subversão, é outra coisa - um saber de senhor.

Assim, interrogamos como o sujeito responde ao desejo do senhor, ao ser tomado como objeto de investigação pelo saber científico, representado no discurso universitário. Ao que acreditamos poder responder, dizendo que o sujeito se objetifica, na medida em que passa a se reconhecer, apenas, pelas categorias de nomeação que o discurso moderno científico lhe oferece. 


\section{Elizabeth dos Reis Sanada}

Alvarez (1995, p. 82) é um dos autores que se dispõe a investigar temas como as toxicomanias, síndromes do pânico, depressão etc., cuja denominação os fecha em si mesmos, os quais são chamados por ele de fenômenos do mundo moderno. A esse respeito, o autor nos diz que "se o sujeito se afirma como 'eu sou' (toxicômano, doente, deprimido etc.), correlativo a um 'eu não penso', como rechaço do inconsciente, reduz-se assim a distância entre o corpo como deserto de gozo e o gozo como fora do corpo".

Sabemos que Lacan, em diversos momentos de sua obra, ao fazer menção ao cogito cartesiano "Penso, logo sou”, buscava marcar, entre outras coisas, de que maneira essa proposição caracterizava a própria condição do sujeito como sujeito dividido. Suprimir o pensar desta operação suporia não só uma ilusão de suturamento, mas também colocaria o sujeito em condição de objeto, pronto a ser consumido pelo aparato capitalista.

Caberia, neste contexto, examinar mais de perto o que se dá, ainda, como resultado ainda da transformação do discurso do mestre, e que Lacan (1972) apresenta como sendo o discurso do capitalista.

Este seria caracterizado, segundo Alvarez (1995, p. 80), "fundamentalmente por uma circularidade que afetaria seus quatro termos e que, entre outras coisas, teria como efeito uma reabsorção contínua de todos os objetos produzidos pelo saber, um discurso, portanto, em que seria possível a relação sexual".

Nas palavras de Tarrab (1992, p. 41), "um discurso no qual um sujeito em sua falta de gozo estrutural demanda ao saber científico a produção de um objeto capaz de um gozo que, sem consequiências, venha a suturar sua castração, sua divisão, sua miséria...”

Lacan abandona, posteriormente, esse matema, justamente por ele não cumprir a condição essencial para ser considerado um discurso, isto é, por nele não existir lugar para a falta, constituindo, portanto, um falso discurso. Embora seja falso, Alvarez (1995) lembra que isto não impede que o mesmo seja sustentado como uma ilusão pelo discurso do mestre, sobretudo naquilo que este se faz representar pela ciência. 
Além disso, Lacan (1972, p. 9) considera que essa pequena inversão entre o $S_{1}$ e o \$, que é o sujeito dividido, é o que basta para que as coisas se ponham a marchar sobre rodas no discurso do capitalista - atendendo ao que seria o desejo do mestre antigo: "que as coisas andem". E acrescenta: "não poderia marchar melhor. Porém, justamente isso marcha demasiado rápido, isso se consome, se consome tão bem que [literalmente] se consome". Nisto reside o fato do discurso capitalista ser considerado por Lacan como o mais astuto dos discursos e, ao mesmo tempo, como aquele que não se sustenta, como o que está "consagrado a arrebentar".

Neste contexto, em que consistirá o discurso do analista e qual será sua função?

Tratar-se-á de um discurso que terá por meta promover a histerização dos demais discursos e apontar para o impossível da relação sexual. Um discurso que nos permitirá dizer, retomando a fala de Freud (citado por Lacan, 1954-1955/1985, p. 16), que

o sujeito não é a sua inteligência, não está no mesmo eixo, é excêntrico. O sujeito como tal é algo diferente de um organismo que se adapta. É outra coisa, e para quem sabe ouvi-lo, a sua conduta toda fala a partir de um outro lugar que não o deste eixo que podemos apreender quando o consideramos como função no indivíduo...

Nas palavras de Vidal (1999, p. 25),

a contribuição específica da psicanálise aos outros discursos consiste em manter a hiância do impossível, fazendo obstáculo ao fechamento imposto pela demanda totalizante do corpo social (...). A psicanálise dá um lugar ao mal-estar na cultura, com irrupção no laço social do real que foi excluído do simbólico. A psicanálise faz função de um real que cada discurso, à sua maneira, denega ou desmente.

Se, pelo lado da ciência, o que se busca é esse Um-tudo, esse Um unificante, do qual Lacan (1969-1970/1992) nos fala, a psicanálise, por sua vez, vem marcar a diferença, vem abrir espaço para a singularidade e para o desejo do sujeito - o que possibilita, inclusive, que se tome conhecimento do sofrimento que se coloca para esses sujeitos. 


\title{
Elizabeth dos Reis Sanada
}

Porque não se trata de outra coisa além de um sofrimento. Todo empreendimento do sujeito por uma busca de recobrimento, só faz reforçar sua condição de sujeito divido. Sofrimento que se inicia num tempo remoto da constituição subjetiva e que Freud, em diversos momentos de sua obra, situa a partir da constatação da falta de pênis na mãe e da natureza assumida, desde então, pelo falo.

Lacan (1965-1966/1998, p. 892) retoma esta questão, dizendo que

o sujeito divide-se ali (...), ao mesmo tempo vendo abrir-se o abismo contra o qual se protegerá com uma fobia, e, por outro lado, cobrindo-o com a superfície que erigirá o fetiche, isto é, a existência do pênis como mantida, ainda que deslocada.

Deste modo, tal estrutura se revelaria na própria dialética entre o discurso da ciência e o da psicanálise, uma vez que esta só nasce a partir da primeira. Essa dialética do fechar e do abrir é, justamente, o que aponta para a falta estrutural do sujeito e para o caráter não totalizador da verdade, que só pode ser dita como meia verdade.

Assim, encerramos com uma frase de Lacan (1969-1970/1992, p. 169), que pensamos condensar o que discutimos até então:

É a partir da clivagem, da separação entre o gozo e o corpo doravante mortificado, a partir do momento em que há jogo de inscrições, marca do traço unário, que a questão se coloca. Não é preciso esperar que o sujeito tenha se revelado bem oculto no nível da verdade do mestre. A divisão do sujeito não é certamente outra coisa senão a ambigüidade radical que se vincula ao próprio termo verdade.

Sanada, E. Dos R. (2004). The truth of science about phychoanalytic lecture. Psicologia USP, 15(1/2), 183-194.

\begin{abstract}
This article intends to demonstrate how to the science has been become main representative of social discourse, taking the function of nomination in the modern world, being responsible for the production of objects that aims to complete the structural lack. It's discussed the connection point between the psychoanalytic and scientific discourse about division of subject between truth and knowledge.
\end{abstract}

Index terms: Science. Psychoanalysis. Truth. Pleasure. 


\section{A 'Verdade’ da Ciência a Partir de uma Leitura Psicanalítica}

Sanada, E. Dos R. (2004). La 'vérité' de la science à partir d'une lecture Psychanalitique. Psicologia USP, 15(1/2), 183-194.

Résumé: Ce travail a pour but situer de quelle façon la science devient le principal représentant du discours social, nomme le sujet dans le monde moderne et devient responsable de la production d'objets qui visent à la suture du manque. Il discute la connexion entre le discours de la psychanalise et celui de la science en ce qui concerne la division du sujet entre savoir et vérité.

Mots-clés: Science. Psychanalyse. Vérité. Jouissance.

\section{Referências}

Alvarez, J. M. (1995). Toxicomanía y pathos del discurso. In Sujeto, goce y modernidad III: De la monotonía a la diversidad (pp. 79-84). Buenos Aires, Argentina: AtuelTya.

Jerusalinsky, A. (s.d.). Psicanálise: Instituição - Transmissão. Porto Alegre, RS. Documento apresentado pela Associação Psicanalítica de Porto Alegre (APPOA).

Lacan, J. (1960). Subversão do sujeito e dialética do desejo no inconsciente freudiano. In Escritos (pp. 807-842). Rio de Janeiro: Jorge Zahar.

Lacan, J. (1972, 6-12 mayo). Del discurso psicoanalítico. Milán: Universitá Degli Studi, via Festa del Perdono.

Lacan, J. (1985). O seminário. Livro 2: O eu na teoria de Freud e na técnica da psicanálise. Rio de Janeiro: Jorge Zahar. (Trabalho original publicado em 19541955)

Lacan, J. (1992). O seminário. Livro 17: O avesso da psicanálise. Rio de Janeiro: Jorge Zahar. (Trabalho original publicado em 1969-1970)

Lacan. J. (1998). A ciência e a verdade. In Escritos (pp. 869-892). Rio de Janeiro: Jorge Zahar. (Trabalho original publicado em 1965-1966).

Lemérer, B. (1999). Algumas reflexões a partir do texto de Freud sobre as teorias sexuais infantis. In A criança e o saber (pp. 13-20). Rio de Janeiro: Revinter.

Tarrab, M. (1994). ...Mírenlos cómo gozan!! In Sujeto, goce y modernidad: Los fundamentos de la clínica. Buenos Aires, Argentina: Atuel-Tya. 


\section{Elizabeth dos Reis Sanada}

Sinatra, E. S. (1994). Variantes del argumento ontológico en la modernidad. In Sujeto, goce y modernidad: Los fundamentos de la clínica (pp. 23-35). Buenos Aires, Argentina: Atuel-Tya.

Sinatra, E. S. (1994). Variantes del argumento ontológico en la modernidad. In Sujeto, goce y modernidad: Los fundamentos de la clínica (pp. 23-35). Buenos Aires, Argentina: Atuel-Tya.

Unterberger, M. (1995). Estatuto del "yo soy" en la toxicomanía y el alcoholismo. In Sujeto, goce y modernidad III: De la monotonía a la diversidad (pp. 61-68). Buenos Aires, Argentina: Atuel-Tya.

Vidal, E. A. (1999). Um outro saber. In A criança e o saber (pp. 21-28). Rio de Janeiro: Revinter.

Recebido em 09.06.2004 Aceito em 06.08.2004 